\title{
Nature and nurture of the interplay between personality traits and major life goals
}

Citation for published version (APA):

Bleidorn, W., Kandler, C., Hülsheger, U. R., Riemann, R., Angleitner, A., \& Spinath, F. M. (2010). Nature and nurture of the interplay between personality traits and major life goals. Journal of Personality and Social Psychology, 99(2), 366-379. https://doi.org/10.1037/a0019982

Document status and date:

Published: 01/08/2010

DOI:

10.1037/a0019982

Document Version:

Publisher's PDF, also known as Version of record

Document license:

Taverne

Please check the document version of this publication:

- A submitted manuscript is the version of the article upon submission and before peer-review. There can be important differences between the submitted version and the official published version of record.

People interested in the research are advised to contact the author for the final version of the publication, or visit the DOI to the publisher's website.

- The final author version and the galley proof are versions of the publication after peer review.

- The final published version features the final layout of the paper including the volume, issue and page numbers.

Link to publication

\footnotetext{
General rights rights.

- You may freely distribute the URL identifying the publication in the public portal. please follow below link for the End User Agreement:

www.umlib.nl/taverne-license

Take down policy

If you believe that this document breaches copyright please contact us at:

repository@maastrichtuniversity.nl

providing details and we will investigate your claim.
}

Copyright and moral rights for the publications made accessible in the public portal are retained by the authors and/or other copyright owners and it is a condition of accessing publications that users recognise and abide by the legal requirements associated with these

- Users may download and print one copy of any publication from the public portal for the purpose of private study or research.

- You may not further distribute the material or use it for any profit-making activity or commercial gain

If the publication is distributed under the terms of Article $25 \mathrm{fa}$ of the Dutch Copyright Act, indicated by the "Taverne" license above, 


\title{
Nature and Nurture of the Interplay Between Personality Traits and Major Life Goals
}

\author{
Wiebke Bleidorn and Christian Kandler \\ Bielefeld University \\ Rainer Riemann and Alois Angleitner \\ Bielefeld University
}

Ute R. Hülsheger
Maastricht University

Frank M. Spinath

Saarland University

\begin{abstract}
Modern personality theories differ in their assumptions about the structure and etiology of the interplay between personality traits and motivational constructs. The present study examined the genetic and environmental sources of the interplay between the Big Five and major life goals concurrently and across time in order to provide a more decisive evaluation of the conflicting assumptions stated in the five-factor theory as opposed to socioanalytic conceptions. Traits and goals were assessed twice across a 5-year period in a sample of 217 identical and 112 fraternal twin pairs from the Bielefeld Longitudinal Study of Adult Twins. About $30 \%$ of the variance in agency and communion life goals was genetic; the remaining variance was due to nonshared environmental effects, whereas shared environmental effects were negligible. Both heritable and environmental variance in goals could partly be accounted for by genetic and nonshared environmental effects on personality traits. Across time, we revealed reciprocal genetic and environmental effects between traits and life goals. In sum, our findings yield partial support for both of the 2 competing personality theories, suggesting a readjusted picture of the interplay between traits and goals.
\end{abstract}

Keywords: five-factor model of personality, major life goals, twins, genetic mediation, personality development

Emphasizing that there is more to personality than traits, Roberts and Robins (2000) posed the question, "What is the conceptual relation between personality traits and goals?" (p. 1286). Interested in the origins, development, and functioning of the constituting units of the personality system, they called for a stronger integration of the classic trait approach (e.g., the five-factor personality model; John, Naumann, \& Soto, 2008; McCrae \& John, 1992) with other personality-relevant constructs, such as long-term goals (Winell, 1987).

Motivational constructs have been long considered an integral part of the study of personality (Allport, 1937; Maslow, 1954; McClelland, 1961; Murray, 1938). Although the conceptual relation between personality traits and motivational constructs has not always been elaborated, both are usually regarded as necessary for a comprehensive description of the person-the former in terms of what a person is like and the latter in terms of what a person wants to become.

Wiebke Bleidorn, Christian Kandler, Rainer Riemann, and Alois Angleitner, Department of Psychology, Bielefeld University, Bielefeld, Germany; Ute R. Hülsheger, Department of Psychology, Maastricht University, Maastricht, the Netherlands; Frank M. Spinath, Department of Psychology, Saarland University, Saarbrüken, Germany.

Correspondence concerning this article should be addressed to Wiebke Bleidorn, Department of Psychology, Bielefeld University, Universitaetsstrasse 25, 33615 Bielefeld, Germany. E-mail: wiebke.bleidorn@ uni-bielefeld.de
Among modern theories of personality, there are two prominent conceptions that noticeably differ in their assumptions about the interplay between traits and goals: Designated neosocioanalytic theory (NST; Hogan \& Roberts, 2000; Roberts, O'Donnell, \& Robins, 2004; Roberts \& Wood, 2006), the first approach assumes goals and traits are related but discrete units of personality at the same level of analysis that independently contribute to life outcomes. To the contrary, the five-factor theory of personality (FFT; McCrae \& Costa, 1999, 2008) considers goals to be causal outcomes of traits, that is, direct or indirect expressions of the more basic personality traits.

In the last decade, only a few studies have responded to the call by Roberts and Robins (2000) to investigate the structural links between goals and traits (e.g., Lüdtke, Trautwein, \& Husemann, 2009; Roberts, O’Donnell, \& Robins, 2004; Romero, Villar, Luengo, \& Gomez-Fraguela, 2009). These studies have consistently revealed significant associations of moderate magnitude between traits and goals both concurrently and across time. As valuable as these findings are, the revealed phenotypic pattern of correlations by itself still does not reveal much about the shared etiologies of traits and goals. However, this is an important issue, because the etiological explanations for the structural links between the constituting units of the personality system can be considered the core and the foundation of both the FFT and the NST.

In the following article, we first introduce major life goals as a conceptual unit of personality and briefly sketch previous findings about their relations with Big Five personality traits. Referring to 
the FFT and the NST, we then outline their diverging hypotheses about the pattern and sources of the interplay between major life goals and personality traits before we finally describe the research design of the present study, which was aimed at illuminating the genetic and environmental sources of the interplay between major life goals and the Big Five.

\section{Major Life Goals in Terms of Agency and Communion}

Similar to personality traits, goals can be described along a hierarchical framework in which rather stable higher order goals embrace several contextualized subgoals that, in turn, can be broken down into specific goals relating to immediate actions (Austin \& Vancouver, 1996). Roberts and Robins (2000) have explicitly focused on a class among the higher order goal concepts, namely, major life goals (see also Lüdtke et al., 2009; Roberts et al., 2004). Major life goals can be defined as "a person's aspirations to shape his or her life context and establish general life structures such as having a career, a family, and a certain kind of lifestyle" (Roberts et al., 2004, p. 542). In contrast to more contextualized midlevel goal units, like current concerns (Klinger, 1977), personal projects (B. R. Little, 1983), or life tasks (Cantor, Norem, Niedenthal, Langston, \& Brower, 1987), major life goals have greater generality, are relatively stable over time, and reflect what people generally strive for in their lives. For instance, a specific life goal would be to have a successful career, whereas an according midlevel goal would be to write a good master's thesis or to finish a job project in time. Furthermore, unlike midlevel goals, which are usually generated ideographically and assessed by means of ipsative response formats, major life goals have usually been assessed by normative importance ratings of standardized sets of goals (Lüdtke et al., 2009; Pöhlmann \& Brunstein, 1997; Roberts et al., 2004; Roberts \& Robins, 2000). Because they thus correspond to broad trait dimensions with respect to breadth, stability, and measurement, major life goals should be most suitable for the purpose of investigating the structural links between traits and goals. That is, both personality traits and major life goals represent broad dispositional constructs: one referring to who people are, the other representing what people desire to become (Roberts \& Robins, 2000).

The assessment of life goals has usually focused on importance ratings of a number of theoretically derived categories that can be organized into the broader domains of agency and communion (Bakan, 1966; Kasser \& Ryan, 1996; Pöhlmann \& Brunstein, 1997; Sheldon \& Cooper, 2008). Agency refers to one's efficacy in dealing with the social and material environment as a separate individual and manifests, for instance, in strivings for achievement, power, fame, or hedonism. This goal domain can be thought of as a blend of McClelland's (1961) needs for achievement and power. Communion, however, is closely associated with McClelland's need for affiliation and refers to one's participation in a larger social network. It manifests, for instance, in strivings for social relationships, intimacy, community, or altruism (Sheldon \& Cooper, 2008).

Previous research has shown that individual differences in importance ratings of agency- and communion-oriented life goals are substantially associated with the Big Five personality domains in theoretically meaningful ways (Lüdtke et al., 2009; Roberts et al.,
2004; Roberts \& Robins, 2000). Correlations suggest that agencyrelated goals are positively related to the traits of Extraversion, Openness, and Conscientiousness and negatively related to Agreeableness. Striving for communion-oriented goals has been shown to be related to Extraversion, Openness, and Agreeableness. No or only small associations have been revealed between Neuroticism and both of the two life goal domains. This probably results from the fact that life goals are necessarily desirable outcomes reflecting approach in contrast to avoidance tendencies, which might be associated with Neuroticism (Roberts \& Robins, 2000).

The few longitudinal studies focusing on the importance of major life goals have reported rank-order stabilities of moderate magnitude in samples of students ranging from .50 to .60 over periods of two to four years (Lüdtke et al., 2009; Roberts et al., 2004). ${ }^{1}$ These coefficients are thus in the same range as stabilities typically revealed for the Big Five in samples of this age group (Roberts \& DelVecchio, 2000). Furthermore, Roberts et al. (2004) found changes in goal importance to be related to changes in personality traits. With respect to reciprocal effects across time, Lüdtke et al. (2009) revealed significant although small effects of prior personality traits on subsequent goal importance but almost no effects of prior goal importance on subsequent personality traits. In sum, these findings draw a first picture of the phenotypic links between traits and goals, suggesting that there are systematic relationships of moderate magnitude, both cross-sectionally and across time.

\section{The Interplay of Traits and Goals in Theories of Personality}

\section{The FFT}

A basic tenet of the FFT is the distinction between basic tendencies and characteristic adaptations. McCrae and Costa (1999, 2008) have assigned personality traits exclusively to the category of basic tendencies representing relatively stable, genetically based dispositions. Both stability and change in basic tendencies should be controlled by biological influences mostly determined by genes, whereas environmental influences should be negligible. To support this strict assumption, the authors have referred to findings on the cross-cultural generality of trait development (e.g., McCrae et al., 2000) as well as to the substantial heritability of personality traits revealed in numerous behavior genetic studies (for reviews, see Bouchard \& Loehlin, 2001; Johnson, Vernon, \& Feiler, 2008).

Goals-like skills, habits, attitudes, roles, or relationshipshave been assigned to the category of characteristic adaptations (McCrae \& Costa, 2008). Characteristic adaptations should represent the concrete manifestations of basic tendencies resulting from the interaction of the genetically based personality traits and the ever-changing demands of the social environment. In contrast to

\footnotetext{
${ }^{1}$ Aside from studies on the importance of major life goals, there are some longitudinal studies on personal goal development using idiographic assessment procedures (e.g., Nurmi \& Salmela-Aro, 2002; Salmela-Aro, Aunola, \& Nurmi, 2007). Because of the individualized nature of these approaches, findings on stability and change in these studies are (a) quite difficult to interpret and (b) hard to compare with results of studies using normative assessment strategies (Lüdtke et al., 2009).
} 
traits that are assumed to be insulated from direct effects of the environment, stability and change in characteristic adaptations should be determined by both genetic and environmental factors.

According to the postulates of the FFT, traits and goals should be significantly related to each other on the phenotypic level. Please note that the FFT does not predict the correlations will be perfect, because goals were not considered to be merely observable reproductions of the trait content but should also reflect specific adaptations to the demands of the environment.

At the biometric level, the FFT assumes goals show substantial heritabilities, but the proportion of genetic effects should be notably smaller than that usually reported for measures of personality traits. Because the Big Five have been major targets of behavior genetic research (Johnson et al., 2008; Krueger \& Johnson, 2008), it is now well-established that about $40 \%$ to $60 \%$ of the variance in self-reports of broad personality traits is genetic in origin, whereas the remaining variance can be almost exclusively traced back to nonshared environmental influences (Bouchard \& Loehlin, 2001). After measurement-specific effects are controlled for, genetically informative multimethod studies have even revealed somewhat higher estimates of heritability in the Big Five (e.g., Riemann, Angleitner, \& Strelau, 1997; Kandler, Riemann, Spinath, \& Angleitner, in press).

In contrast to the vast amount of behavior genetic studies on personality traits, there are, however, no studies on the heritability of major life goals. As a result, three further hypotheses of the FFT are still untested: First, the genetic effects on goals should be completely accounted for by the basic tendencies. This implies that there should be no unique genetic effects on goals independent of those on measures of personality traits. Second, there should be no common environmental effects influencing measures of both traits and goals, because the FFT assumes personality traits are immune to systematic effects of the environment. Third, there should be genetically and environmentally mediated effects of prior traits on subsequent goals but not vice versa. That is, personality traits should be resistant to genetically and environmentally mediated effects of prior life goals.

\section{The NST}

According to the NST (Roberts \& Wood, 2006), four units of analysis represent the core components of personality, namely, traits, motives, abilities, and narratives. Each of the domains should be hierarchically organized, entailing broad, midlevel, and narrow constructs that should subsume almost all categories describing individual differences. In contrast to the FFT, in the NST, none of these elements are conceptualized as being causally superior to any other. In the NST framework, Big Five traits and major life goals actually represent two discrete but related units of personality that are positioned at the same hierarchical level (Roberts \& Robins, 2000).

Both traits and goals should be influenced by genetic and environmental effects. Besides these direct influences of genes and the environment, there should be reciprocal effects between goals and traits that promote developmental processes in both of them. According to Roberts et al. (2004), the most prevailing interaction between traits and goals can be captured in terms of the corresponsive principle (see also Caspi, Roberts, \& Shiner, 2005; Roberts \& Wood, 2006). This principle states that those traits that lead a person to pursue certain life goals should themselves be deepened by the outcomes and experiences gained while striving for these goals. For example, a person who is high in Agreeableness may strongly pursue communion-oriented goals, leading him or her into a charitable work context that demands and rewards social and caring behavior. By meeting these demands, his or her agreeable tendencies will then, in turn, be reinforced in this role context.

Implying that people adapt their life goals in accordance with their personality traits, the initiation of corresponsive processes appears to be closely in line with the assumptions of the FFT. More controversial than the corresponsive principle is thus the possibility that specific changes in life goals that are independent of people's personality traits may affect changes in personality traits. For example, a woman who got pregnant may increase her strivings for certain communion-oriented goals independent of her preexisting personality trait levels. Pursuing these goals might lead her into social contexts requiring and rewarding social and caring parenting behavior. Successfully achieving these goals might then also affect her general level of Agreeableness.

The following hypotheses on the links between traits and goals can be derived from the conception of the NST: First, like the FFT, the NST assumes major life goals and the Big Five are significantly related in meaningful ways at the phenotypic level (Roberts \& Robins, 2000). At the biometric level, goals are also assumed to show substantial heritability. But in contrast to the FFT, the NST does not predict notable differences between the heritability of traits and goals. Third, assuming goals and traits are related but discrete elements of the personality system, there should be both common and unique genetic effects on traits and goals. That is, the genetic effects on goals should not be completely accounted for by traits, but there should also be specific genetic effects on goals that are independent of the genetic effects on the Big Five traits. Fourth, common environmental effects should influence measures of both traits and goals. Finally, the NST predicts reciprocal cross-time relationships between traits and goals. That is, there should be contributions of genetic and environmental effects from prior personality traits to subsequent goals but also genetic and environmental effects from prior life goals on later personality traits.

\section{The Present Study}

The present research was aimed at elucidating the genetic and environmental influences on the structural links between personality traits and major life goals in order to provide a critical test of the conflicting assumptions stated in the FFT as opposed to the NST. We assessed the Big Five and the importance of agency- and communion-oriented life goals twice across a five-year period in a sample of twins reared together. By using this multivariate longitudinal-biometric design, we were able to disentangle the genetic and environmental effects on the links between traits and goals concurrently and across time.

\section{Method}

\section{Participants and Procedure}

The sample was drawn from the ongoing Bielefeld Longitudinal Study of Adult Twins, which was initiated in 1993 with a sample 
of 1,118 monozygotic (MZ) and dizygotic (DZ) German twins who were reared together. This study has been described previously (Bleidorn, Kandler, Riemann, Angleitner, \& Spinath, 2009; Spinath, Wolf, Angleitner, Borkenau, \& Riemann, 2005).

For the present analyses, we used data from complete twin pairs gathered at the third and fourth assessment waves, which were 5.7 years apart $(S D=0.3)$. At these two measurement occasions (referred to as Time 1 and Time 2), participants provided selfreports on their personality traits and their major life goals. Participants older than 75 years at Time 2 (and thus older than 69 years at Time $1 ; n=9$ pairs) were excluded from analyses. Analyses were performed on 329 intact twin pairs at Time 1 (female $n=269$, male $n=60$ ) and 193 intact twin pairs at Time 2 (response rate $=58.6 \%$; female $n=162$, male $n=31$ ). At Time 1 , the sample consisted of $217 \mathrm{MZ}$ and $112 \mathrm{DZ}$ twin pairs (27 opposite-sex pairs) with a mean age of 38.7 years $(S D=12.5)$. At Time 2, the sample consisted of $132 \mathrm{MZ}$ and $60 \mathrm{DZ}$ twins (15 opposite-sex pairs) with a mean age of 45.5 years $(S D=12.9)$. Zygosity was determined by a self-report questionnaire (Onisczenko, Angleitner, Strelau, \& Angert, 1993) that assesses the frequency with which the twins were confused by different relatives, teachers, and peers across the life span as well as physical similarity criteria (concordance with genetic finger printing data is 93.2\%; Becker et al., 1997).

Attrition analyses revealed no significant differences when comparing participants and nonparticipants from Time 2 on each scale of the personality and goal measures gathered at Time 1 . Regarding demographic variables, we also found no differences in zygosity and sex but did in the mean age of participants, indicating that dropout was larger for younger individuals, $t(309)=3.24, p<.05$, $d=0.37$. The size of this effect, however, would generally be considered small (Cohen, 1992).

\section{Measures}

Big Five dimensions of personality. To assess the Big Five personality dimensions of Neuroticism, Extraversion, Openness, Agreeableness, and Conscientiousness, we administered the German version of the Revised NEO Personality Inventory (NEO
PI-R; Costa \& McCrae, 1992; Ostendorf \& Angleitner, 2004) at both measurement occasions. The NEO PI-R contains 240 items, grouped into 30 facet scales that are hierarchically organized under the five domain scales of the five-factor personality model. Responses are made on a 5-point Likert-type scale ranging from $1=$ strongly disagree to $5=$ strongly agree. All analyses were performed on the five 48-item domain scales (sum scores). Table 1 shows the internal consistencies at Times 1 and 2 as well as the stability coefficients (unadjusted for measurement error) for the five domains. As expected for this age group (Terracciano, Costa, \& McCrae, 2006), internal consistencies as well as five-year stabilities were above .80 for each of the five scales.

Table 1 also displays the results of missing values analyses (MCAR tests; R. J. A. Little, 1988) on all available data from intact twin pairs across Times 1 and 2 . None of the five MCAR tests for the NEO PI-R scales were significant ( $p>.05)$, suggesting that dropout can be assumed to be completely at random.

Communion and Agency goals. To assess the importance of participants' agentic and communal life goals, we administered the self-report questionnaire GOALS (Pöhlmann \& Brunstein, 1997) at both measurement occasions. The theoretical basis of GOALS was geared to Bakan's (1966) distinction between Agency and Communion. Both higher order domains are represented by three subscales referring to the motive classifications of McClelland (1985) and McAdams (1988). Each of the six subscales consists of four life-goal descriptions (starting with "I want to" and followed by the particular life goal), which have been carefully selected from a larger item pool using a combination of internal consistency and factor analysis (Pöhlmann \& Brunstein, 1997). The subscales of Power (e.g., "have prestigious positions"), Achievement (e.g., "develop my skills"), and Variation (e.g., "lead an exciting life") pertain to agency; the subscales of Altruism (e.g., "help other people"), Affiliation (e.g., "be friends with many people"), and Intimacy (e.g., "receive affection and love") merge to form the domain of communion. Participants were asked to rate the importance of each life goal according to its relevance to their long-term or lifetime orientation on a 5-point Likert-type scale ranging from $1=$ not important to $5=$ very important.

Table 1

Internal Consistency, Rank-Order Stability, and Results of Missing Completely at Random (MCAR) Tests for Revised NEO Personality Inventory and GOALS Scales

\begin{tabular}{|c|c|c|c|c|c|c|}
\hline \multirow[b]{2}{*}{ Scale } & \multicolumn{2}{|c|}{$\begin{array}{l}\text { Internal consistency } \\
\quad(\text { Cronbach's } \alpha)\end{array}$} & \multirow{2}{*}{$\begin{array}{c}\text { Rank-order stability } \\
\left(r_{12}\right)\end{array}$} & \multicolumn{3}{|c|}{ MCAR statistics } \\
\hline & Time 1 & Time 2 & & $x^{2}$ & $d f$ & $p$ \\
\hline Neuroticism & .93 & .93 & .83 & 3.32 & 8 & .91 \\
\hline Extraversion & .89 & .88 & .83 & 12.01 & 8 & .15 \\
\hline Openness & .88 & .87 & .81 & 15.19 & 8 & .06 \\
\hline Agreeableness & .86 & .87 & .81 & 13.26 & 8 & .10 \\
\hline Conscientiousness & .89 & .86 & .81 & 11.91 & 8 & .16 \\
\hline Agency & .85 & .83 & .64 & 15.25 & 8 & .06 \\
\hline Communion & .84 & .86 & .61 & 8.41 & 8 & .39 \\
\hline
\end{tabular}

Note. Cronbach's $\alpha$ and rank-order stabilities $\left(r_{12}\right)$ were estimated by using split samples such that members of a twin pair did not enter the same analysis. That is, each sibling was randomly assigned to one of two subsamples: $\operatorname{twin}_{i}$ and $\operatorname{twin}_{j}$. The table shows the averaged values across split samples (for Time $1, \operatorname{twin}_{i} n=$ 329, $\operatorname{twin}_{j} n=329$; for Time 2, $\operatorname{twin}_{i} n=193, \operatorname{twin}_{j} n=193$ ). MCAR tests (R. J. A. Little, 1988) were calculated for all available data from complete twin pairs $(N=329)$. 
Several studies have shown the GOALS to be a reliable and valid instrument for the assessment of long-term goals in terms of agency and communion orientation (e.g., Bleidorn, 2009; Hofer \& Chasiotis, 2003). Even for the 6 four-item subscales, internal consistencies $(M \alpha=.75)$ as well as test-retest reliabilities $(M$ 2-month test-retest correlation $=.78$ ) have been found to be quite satisfying (Pöhlmann \& Brunstein, 1997).

In the present study, both the Agency and Communion domain scales showed satisfactory internal consistencies at Time 1 and 2 (see Table 1). Rank-order stabilities were notably lower than those of the NEO PI-R scales, indicating that major life goals were less stable than personality traits in this age group. ${ }^{2}$ Regarding the MCAR tests, results suggest that dropout can be assumed to be completely at random $(p>.05)$.

\section{Analyses}

We first calculated the phenotypic bivariate correlations between the two GOALS scales and each of the five NEO PI-R domains at Time 1 and Time 2 on data from split samples, such that members of a twin pair did not enter the same analysis (i.e., each sibling was randomly assigned to one of two subsamples). We used Amos 17.0 (Arbuckle, 2007) to estimate the bivariate correlation coefficients in a multisample approach via maximum likelihood by fitting the model in each sample but doing so simultaneously for both groups. That is, we explicitly tested if the correlations generated from split-sample analyses differ substantially between the subsamples of twin siblings.

Prior to biometric analyses, raw scores were adjusted for sex as well as linear and quadratic age effects within each measurement occasion, because age and gender effects can act to increase variance and distort twin similarity. This correction procedure did not affect the age differences across measurement occasions but only adjusted for age effects at a given point in time.

Our quantitative genetic analyses were based on twin methodology assuming that the variance of a phenotype can be decomposed into at least three variance components, namely, additive genetic effects of multiple genes (A), shared environmental influences common to each member of a twin pair (C), and nonshared environmental effects unique to each individual (E). Because the nonshared environmental component is modeled as residual variance, it also includes variance attributable to random error of measurement (Neale \& Maes, 2004).

Biometric models of this form are based on several assumptions: First, MZ twins are assumed to share trait-relevant environmental influences to the same degree as DZ twins do (e.g., Borkenau, Riemann, Angleitner, \& Spinath, 2002). Second, there should be no assortative mating for the variables of interest. Although there is evidence for marital resemblance for certain personality-related variables, such as attitudes, positive assortment for most personality traits is considered to be effectively random (Johnson et al., 2008). The third assumption is that there is no gene-environment correlation or interaction. It should be noted that the nonrecognition of these effects could obscure potential differences between underlying subgroups within the data. However, the primary aim of the present study was to examine the aforementioned hypotheses at overall population levels. Finally, it is assumed that there are no nonadditive genetic effects (due to dominance or epistasis). Previous studies have reported quite inconsistent findings and revealed the lack of power to detect nonadditive genetic effects in the standard twin design (Kandler, Riemann, \& Kämpfe, 2009; Martin, Eaves, Kearsey, \& Davies, 1978).

Genetic and environmental contributions to the relationships between major life goals and personality traits were examined from cross-sectional and longitudinal perspectives by using structural equation modeling. Cross-sectional models were fitted to the $\mathrm{MZ}$ and DZ phenotypic variance-covariance matrices on data of complete twin pairs at Time 1 and Time 2 via maximum likelihood analysis using Amos 17.0 (Arbuckle, 2007). Overall model fit was evaluated by the root mean square error of approximation (RMSEA) indicating a good fit when values are smaller than .05. Nested models were compared by means of the likelihood ratio test (LR test or chi-square difference test). For descriptive comparisons among unnested models, we used the Akaike information criterion (AIC $=\chi^{2}-2 d f$ ), choosing the model with the most negative AIC value.

Longitudinal models were fitted to the raw data of intact twin pairs to exploit all available information across Time 1 and Time 2. That is, we used the full information maximum likelihood option implemented in Amos on the condition that missing values were completely at random (see Table 1). Full information maximum likelihood uses all available information of the observed data, correcting for potential statistical bias due to missing data. Comparative fit among different competing models was evaluated by means of the AIC.

Univariate analyses. We first applied a univariate behavioral genetic model to assess the additive genetic $\left(g^{2}\right)$, shared environmental $\left(c^{2}\right)$, and nonshared environmental $\left(e^{2}\right)$ effects on Agency and Communion. In search of the model with the smallest number of parameters that match the observed data as closely as possible, we used standard procedures to test reduced models (Neale \& Maes, 2004).

Cross-sectional multivariate analyses. To examine the concurrent genetic and environmental overlap between the five NEO PI-R domains and each of the two goal categories, we fitted six-variable Cholesky decomposition models for both Time 1 and Time 2 (see Figure 1). Representing the structural links between the Big Five and major life goals as postulated in the FFT, this model provides two pieces of information: First, it allowed us to partition the shared variance between trait and goal phenotypes into their genetic and environmental components. These indicate the degree to which genetic and environmental influences on goals were accounted for by personality traits, which is represented by the $\mathrm{g}_{16}-\mathrm{g}_{56}$ and $\mathrm{e}_{16}-\mathrm{e}_{56}$ paths from additive genetic $\left(\mathrm{G}_{1}-\mathrm{G}_{5}\right)$ and nonshared environmental $\left(E_{1}-E_{5}\right)$ factors linking trait and goal phenotypes. Common environmental effects influencing both personality traits and goals were exclusively modeled as nonshared,

\footnotetext{
${ }^{2}$ Stability coefficients can be ambiguous because of the difficulty in differentiating between true change and measurement error (Watson, 2004). However, internal consistencies of the two higher order scales were in the range of those of the five NEO PI-R domains. Furthermore, previous reports on the average 2-month test-retest reliabilities (.78) of the six GOALS subscales were quite satisfying (Pöhlmann \& Brunstein, 1997). These findings support our conclusion that the smaller 5-year stability coefficients for Agency and Communion not only reflect greater impairment by measurement error but in fact indicate greater long-term instability of goals compared with personality traits.
} 


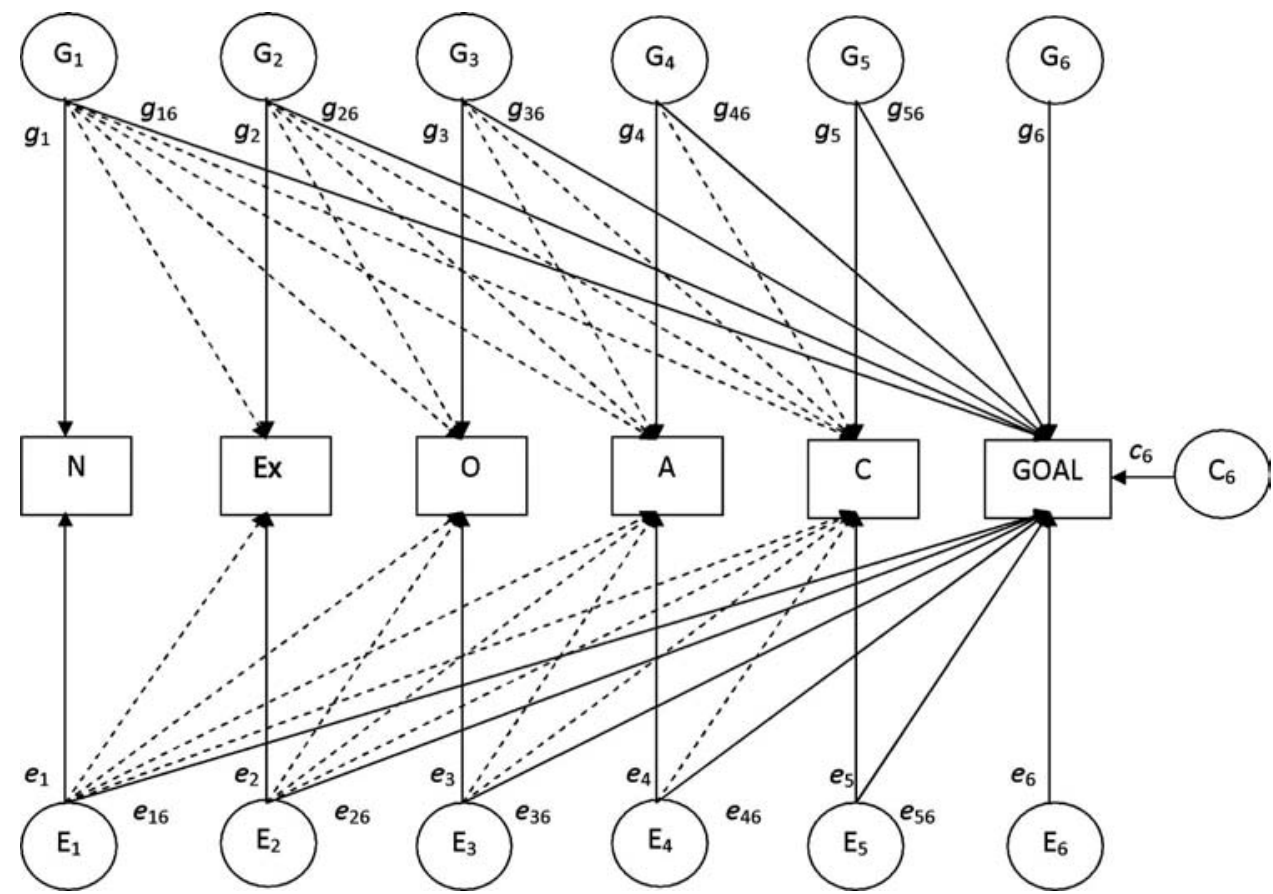

Figure 1. Initial multivariate Cholesky decomposition model of the associations between Revised NEO Personality Inventory (NEO PI-R) domain scales ( $\mathrm{N}=$ Neuroticism; Ex = Extraversion; $\mathrm{O}=$ Openness; $\mathrm{A}=$ Agreeableness; $\mathrm{C}=$ Conscientiousness) and the two GOALS scales (GOAL) at one point in time. For the sake of parsimony, the model is only shown for one member of a twin pair. In this model, the variance of the goal phenotypes is decomposed into additive genetic variance components $(\mathrm{G})$ and nonshared environmental variance components (E) due to additive genetic and nonshared environmental effects common to the five NEO PI-R domains and the specified goal phenotype $\left(g_{16^{-}} g_{56}\right.$ and $\left.e_{16}-e_{56}\right)$ and the additive genetic, nonshared, and shared environmental effects specific to the goal phenotype $\left(g_{6}, e_{6}, c_{6}\right)$.

because shared environmental influences on the Big Five can be considered negligible (Bouchard \& Loehlin, 2001).

The model also allowed us to decompose the specific variance of the goal phenotypes into genetic and environmental variance components represented by the $\mathrm{g}_{6}, \mathrm{c}_{6}$, and $\mathrm{e}_{6}$ paths from the additive genetic $\left(\mathrm{G}_{6}\right)$, shared $\left(\mathrm{C}_{6}\right)$, and nonshared environmental $\left(\mathrm{E}_{6}\right)$ factors unique to the goal phenotype. These provide estimates of the specific genetic and environmental influences on the respective goal domains that are independent from the effects on personality traits. The dashed lines in Figure 1 illustrate that this model allowed for genetic and environmental paths among the five personality trait variables, although these were not the focus of the present research. Please note that the order of the five manifest trait variables in this Cholesky decomposition model did not affect our results, because our hypotheses did not refer to the associations of goals with specific trait domains but to the associations with the Big Five on the whole.

To determine the best-fitting model of genetic and environmental relations between personality traits and major life goals, we compared a series of reduced models against the initial model. In doing so, we explicitly tested if there were (a) specific genetic effects on the two goal domains or if the genetic variance in goals was completely contributed by personality traits and (b) if there were substantial common environmental effects on traits and goals.
Longitudinal multivariate analyses. Capitalizing on our multivariate two-wave design, we first examined if there were genetic and environmental effects specific to antecedent life goals affecting subsequent personality traits. Figure 2 shows a path diagram of the three-variable Cholesky decomposition model that we used to examine each of the 10 different goal-trait cross-time relationships ( 2 Goal Dimensions at Time $1 \times 5$ Personality Traits at Time 2). This model allowed us to estimate the cross-variablecross-time effects by decomposing the variance of each of the five trait phenotypes at Time 2 into genetic and environmental components due to different additive genetic and nonshared environmental effects. Specifically, the phenotypic variance of each Time 2 personality trait was parsed into genetic and environmental variance components contributed from the corresponding trait phenotype at Time 1 on the one hand (represented by the $g_{\mathrm{NEO} 1 \mathrm{NEO} 2}$ and $e_{\mathrm{NEO} 1 \mathrm{NEO} 2}$ paths) and from the specified goal phenotype at Time 1 on the other hand (represented by the $g_{\text {GOA1NEO2 }}$ and $e_{\mathrm{GOA} 1 \mathrm{NEO} 2}$ paths). The latter reflect the cross-variable-cross-time effects, which were estimated while controlling for the concurrent relationships between the specified trait and goal domains at Time 1 (represented by the $g_{\mathrm{NEO} 1 \mathrm{GOA} 1}$ and $e_{\mathrm{NEO} 1 \mathrm{GOA} 1}$ paths). We tested the significance of these effects by comparing the initial unrestricted model with a series of reduced models in which the genetic and/or environmental cross-variable-cross-time effects were set equal to zero. 


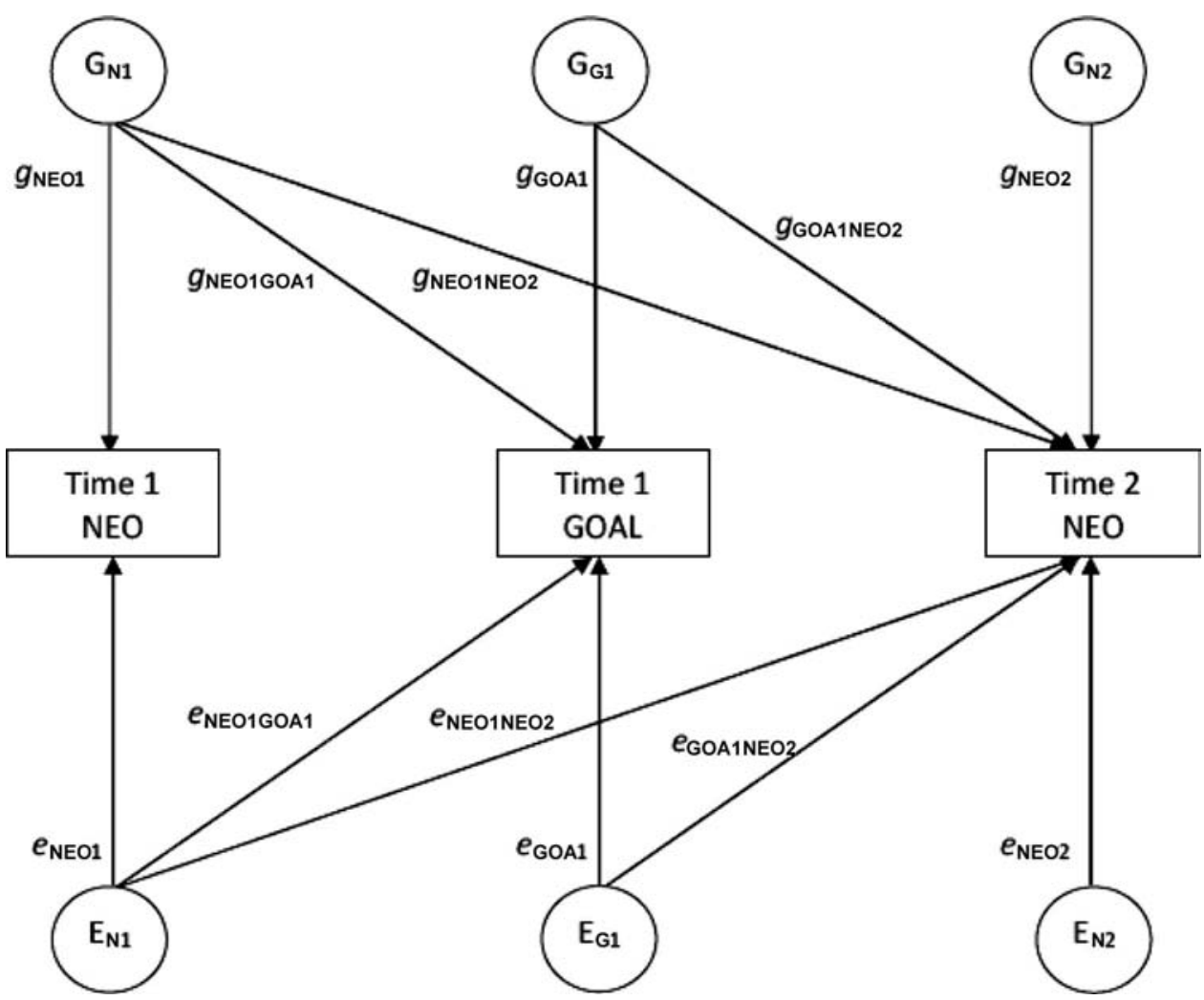

Figure 2. Initial multivariate Cholesky decomposition model of the associations between the two GOALS scales (GOAL) and each of the five Revised NEO Personality Inventory domain scales (NEO) across Time 1 and Time 2. For simplicity, the model is only shown for one member of a twin pair and shared environmental effects were omitted from this diagram. In this model, the variance of the trait phenotypes at Time 2 is decomposed into additive genetic $(\mathrm{G})$ and nonshared environmental $(\mathrm{E})$ variance components because of the additive genetic and nonshared environmental effects unique at Time 2 and those common with the two different Time 1 phenotypes. The cross-variable-cross-time effects were represented by the $g_{\mathrm{GOA} 1 \mathrm{NEO} 2}$ and $e_{\mathrm{GOA} 1 \mathrm{NEO} 2}$ paths, respectively, reflecting the additive genetic and nonshared environmental contributions from a goal domain at Time 1 to a trait domain at Time 2. These effects were estimated while controlling for the concurrent relationships between traits and goals at Time $1\left(g_{\mathrm{NEO} 1 \mathrm{GOA} 1}\right.$ and $\left.e_{\mathrm{NEO} 1 \mathrm{GOA} 1}\right)$ as well as for the stability of the specified trait domain $\left(g_{\mathrm{NEO} 1 \mathrm{NEO} 2}\right.$ and $\left.e_{\mathrm{NEO} 1 \mathrm{NEO} 2}\right)$.

The same kind of model was used to analyze the reverse effects of antecedent personality traits on subsequent goals while controlling for their concurrent relationships at Time 1 . That is, we also ran a series of analyses for each of the 10 different trait-goal cross-time relationships (5 Personality Traits at Time $1 \times 2$ Goal Dimensions at Time 2) to estimate the genetic and environmental effects from the five Time 1 personality traits on the two goal domains at Time 2.

At this point, it should be noted that our model did not provide a critical test of the corresponsive principle because modeling these reciprocal mechanisms appropriately necessitates a minimum of three measurement occasions. However, the available data allowed us to address a rather controversial question, namely, if there were genetic and/or environmental effects unique to traits and life goals at Time 1 accounting for the variance in the other phenotype assessed at Time 2 over and above the stable genetic and environmental effects on the respective variable.

\section{Results}

\section{Bivariate Phenotypic Correlations Between Traits and Goals}

Multigroup analyses, in which parameters generated from splitsample analyses were simultaneously fitted to both groups, consistently revealed that a model in which both subsamples were equated on all parameters fits the data well (RMSEA $<.05$ ) for each of the 20 bivariate correlations between the two GOALS scales and the five NEO PI-R domains assessed at Time 1 and Time 2. Thus, only one coefficient is reported for both groups in Table 2 .

As could be expected on the grounds of previous research (Roberts et al., 2004; Roberts \& Robins, 2000), importance of agentic goals was positively related to Extraversion, Openness, and Conscientiousness but negatively related to Agreeableness. Communion goals were positively related to Extraversion, Open- 
Table 2

Phenotypic Concurrent Correlations Between Revised NEO Personality Inventory (NEO PI-R) and GOALS Scales at Time 1 and Time 2

\begin{tabular}{|c|c|c|c|c|c|c|c|c|c|c|}
\hline \multirow[b]{3}{*}{ GOALS scale } & \multicolumn{10}{|c|}{ NEO PI-R scale } \\
\hline & \multicolumn{2}{|c|}{ Neuroticism } & \multicolumn{2}{|c|}{ Extraversion } & \multicolumn{2}{|c|}{ Openness } & \multicolumn{2}{|c|}{ Agreeableness } & \multicolumn{2}{|c|}{ Conscientiousness } \\
\hline & $\mathrm{T} 1$ & $\mathrm{~T} 2$ & $\mathrm{~T} 1$ & $\mathrm{~T} 2$ & $\mathrm{~T} 1$ & $\mathrm{~T} 2$ & $\mathrm{~T} 1$ & $\mathrm{~T} 2$ & $\mathrm{~T} 1$ & $\mathrm{~T} 2$ \\
\hline Agency & .05 & -.09 & $.43^{* * * *}$ & $.30^{* * * *}$ & $.38^{* * * * *}$ & $.28^{* * * *}$ & $-.17^{* * * *}$ & $-.20^{* * * *}$ & $.17^{* * * *}$ & $.25^{\text {**** }}$ \\
\hline Communion & -.05 & -.06 & $.45^{* * *}$ & $.38^{* * * *}$ & $.24^{* * * * * *}$ & $.19^{* * * * *}$ & $.40^{* * * *}$ & $.32^{* * * *}$ & .03 & .07 \\
\hline
\end{tabular}

Note. Bivariate correlation coefficients were estimated via maximum likelihood on data of split samples (for Time 1, twin $n=329$, twin $n=329$; for Time 2, $\operatorname{twin}_{i} n=193, \operatorname{twin}_{j} n=193$ ). Multigroup analyses, in which parameter estimates generated from split-sample analyses were simultaneously fitted to both groups, consistently revealed that a model in which twin ${ }_{i}$ and twin $_{j}$ were equated on all parameters fitted the data well (root mean square error of approximation $<.05)$. $\mathrm{T} 1=$ Time $1 ; \mathrm{T} 2=$ Time 2 . **** $p<.001$.

ness, and Agreeableness. Also consistent with previous research, the pattern of correlations was quite similar at both times and there were no significant correlations between Neuroticism and both of the goal domains.

\section{Univariate Biometric Analyses}

Table 3 shows the results of the best-fitting univariate models we applied for the two GOALS scales at Time 1 and Time 2. For both scales, an AE model containing additive genetic and nonshared environmental parameters provided the best fit to the data as evaluated by the LR test, the RMSEA, and the AIC.

The heritability estimates of Agency were moderate in magnitude, with roughly one third of the variance due to additive genetic effects and two thirds due to nonshared environmental effects at both Time 1 and Time 2. At Time 1, about a third of the variance in Communion was due to additive genetic effects, whereas the magnitude of heritability was notably smaller at Time 2 . For both scales, we found no significant effects of the shared environment.

\section{Cross-Sectional Multivariate Biometric Analyses}

Table 4 presents the results of the best-fitting six-variable Cholesky decomposition models we applied for both goals dimensions at Time 1 and Time 2 . Fit statistics consistently suggested that a model allowing for additive genetic and nonshared environmental mediation of the relationships between traits and goals provided the best fit to the data for Agency and Communion at both points in time. That is, reduced models in which all genetic and/or all environmental paths linking traits and the specified goal domain were set equal to zero resulted in a significant decrease in fit. Furthermore, setting the unique genetic effects on goals equal to zero also resulted in a poorer fit than the initial model (see Figure 1) for both goal dimensions and both points in time.

Variance partitioning revealed that at Time 1, about $41 \%$ of the additive genetic effects on Agency and even $68 \%$ of the additive genetic effects on Communion were accounted for by the heritable variance in personality traits $\left(g_{\mathrm{c}}{ }^{2} /\left[g_{\mathrm{c}}{ }^{2}+g_{\mathrm{s}}{ }^{2}\right]\right)$. Common nonshared environmental effects of traits and goals made up 25\% and $19 \%$ of the total nonshared environmental variance in Agency and Com-

Table 3

Best-Fitting Univariate Biometric Models for Agency and Communion at Time 1 and Time 2

\begin{tabular}{|c|c|c|c|c|c|c|c|c|}
\hline \multirow[b]{2}{*}{ Scale } & \multirow[b]{2}{*}{ Best fit model } & \multicolumn{4}{|c|}{ Fit statistics } & \multicolumn{3}{|c|}{ Effects (in \%) } \\
\hline & & $x^{2}$ & $d f$ & RMSEA & AIC & $g^{2}$ & $c^{2}$ & $e^{2}$ \\
\hline \multicolumn{9}{|c|}{ Time 1} \\
\hline Agency & $\mathrm{AE}$ & 0.96 & 4 & 0.000 & -7.04 & 29 & - & 71 \\
\hline Communion & $\mathrm{AE}$ & 1.05 & 4 & 0.000 & -6.95 & 36 & - & 64 \\
\hline \multicolumn{9}{|c|}{ Time 2} \\
\hline Agency & $\mathrm{AE}$ & 2.26 & 4 & 0.000 & -5.74 & 33 & - & 67 \\
\hline Communion & $\mathrm{AE}$ & 0.82 & 4 & 0.000 & -7.18 & 26 & - & 74 \\
\hline
\end{tabular}

Note. Maximum likelihood analyses on data of complete twin pairs. At Time 1, $N=329$ (for MZ twins, $n=$ 217; for DZ twins, $n=112$ ); at Time $2, N=193$ (for MZ twins, $n=112$; for DZ twins, $n=61$ ). A = additive genetic influence; $\mathrm{E}=$ nonshared environmental influence; $\mathrm{RMSEA}=$ root mean square error of approximation; $\mathrm{AIC}=$ Akaike information criterion; $\mathrm{MZ}=$ monozygotic; $\mathrm{DZ}=$ dizygotic; Effects (in \%) $=$ percentage of total phenotypic variance explained by additive genetic $\left(g^{2}\right)$, shared $\left(c^{2}\right)$, and nonshared environmental $\left(e^{2}\right)$ effects. Dashes indicate parameters that were not significant and thus dropped from the final model. 
Table 4

Best-Fitting Six-Variable Cholesky Decomposition Models for the Five Revised NEO Personality Inventory (NEO PI-R) Scales and Each of the Two GOALS Scales at Time 1 and Time 2

\begin{tabular}{|c|c|c|c|c|c|c|c|c|c|}
\hline \multirow[b]{3}{*}{ Scale } & \multirow[b]{3}{*}{ Best fit model } & \multirow{2}{*}{\multicolumn{4}{|c|}{ Fit statistic }} & \multicolumn{4}{|c|}{ GOALS variance partition (in \%) } \\
\hline & & & & & & \multicolumn{2}{|c|}{$\begin{array}{l}\text { Explained by } \\
\text { NEO PI-R }\end{array}$} & \multicolumn{2}{|c|}{$\begin{array}{l}\text { Unique to } \\
\text { GOALS }\end{array}$} \\
\hline & & $x^{2}$ & $d f$ & RMSEA & AIC & $g_{\mathrm{c}}^{2}$ & $e_{\mathrm{c}}^{2}$ & $g_{\mathrm{s}}^{2}$ & $e_{\mathrm{s}}^{2}$ \\
\hline \multicolumn{10}{|c|}{ Time 1} \\
\hline Agency & $\mathrm{AE}$ & 101.65 & 114 & 0.000 & -126.35 & 12 & 18 & 17 & 53 \\
\hline Communion & $\mathrm{AE}$ & 101.23 & 114 & 0.000 & -126.77 & 26 & 12 & 12 & 50 \\
\hline \multicolumn{10}{|c|}{ Time 2} \\
\hline Agency & $\mathrm{AE}$ & 109.00 & 114 & 0.000 & -119.00 & 19 & 11 & 15 & 55 \\
\hline Communion & $\mathrm{AE}$ & 119.15 & 114 & 0.015 & -108.85 & 19 & 17 & 9 & 55 \\
\hline
\end{tabular}

Note. Maximum likelihood analyses on data of complete twin pairs. At Time $1, N=329$ (for MZ twins, $n=217$; for DZ twins, $n=112$ ), and at Time 2, $N=193$ (for MZ twins, $n=112$; for DZ twins, $n=61$ ). A = additive genetic influence; $\mathrm{E}=$ nonshared environmental influence; RMSEA $=$ root mean square error of approximation; AIC = Akaike information criterion; $\mathrm{MZ}=$ monozygotic; DZ $=$ dizygotic; GOALS variance partition (in $\%)=$ partitioning of the total phenotypic variance of Agency and Communion into genetic $\left(g_{\mathrm{c}}^{2}\right)$ and environmental $\left(e_{\mathrm{c}}^{2}\right)$ effects that are common with the five NEO PI-R domain scales and genetic $\left(g_{\mathrm{s}}^{2}\right)$ and environmental $\left(e_{\mathrm{s}}^{2}\right)$ effects that are specific to the two GOALS scales.

munion, respectively $\left(e_{\mathrm{c}}{ }^{2} /\left[e_{\mathrm{c}}{ }^{2}+e_{\mathrm{s}}^{2}\right]\right)$. These findings also imply that $59 \%$ of the genetic variance in Agency and $32 \%$ of the genetic variance in Communion at Time 1 was unique to these goals dimensions and thus independent of the genetic influences on traits.

At Time 2, the heritability of Agency was somewhat larger than at Time 1. Results suggested that the amount of genetic variance explained by traits had increased absolutely as well as relatively (55\%), whereas the degree of common nonshared environmental effects had decreased (16\%). Although the unique genetic effects were somewhat smaller compared with effects at Time 1, they still accounted for $15 \%$ of the total phenotypic variance, that is, for $45 \%$ of the total genetic variance in Agency at Time 2.

Compared with Time 1, the heritability of Communion had decreased in absolute terms. The variance partitioning into common and unique components led, however, to nearly the same proportions as for Time 1 . That is, $68 \%$ of the additive genetic effects were accounted for by the heritable variance in personality traits and $32 \%$ were unique to this goal category. Of the nonshared environmental effects, $23 \%$ were accounted for by the corresponding effects on traits and $77 \%$ were unique to Communion.

\section{Longitudinal Multivariate Biometric Analyses}

With our third biometric model, we aimed to examine the genetically and environmentally mediated cross-variable-crosstime effects of prior goals on subsequent traits and vice versa. In a first series of analyses, we tested if there were genetic and environmental effects on the five trait phenotypes at Time 2 accounted for by the two goal domains assessed at Time 1 (controlling for their concurrent relationships at Time 1). To determine the best-fitting and most parsimonious models with respect to the AIC, we compared a series of reduced models in which the genetic, the environmental, or both kinds of cross-variable-crosstime effects of the initial Cholesky decomposition model (see Figure 2) were set equal to zero. In the final models, all parameter estimates were significant at $p<.05 .^{3}$
We found a significant, although small, genetically mediated effect from Time 1 Agency on Time 2 Conscientiousness $\left(g_{\text {GOA } 1 \mathrm{NEO} 2}=.15, p<.01\right)$. This effect indicated that about $4 \%$ of the total genetic variance in Conscientiousness at Time 2 was contributed by genetic effects unique to Time 1 Agency $\left(g_{\mathrm{GOA} 1 \mathrm{NEO} 2}^{2} /\left[g_{\mathrm{GOA} 1 \mathrm{NEO} 2}^{2}+g_{\mathrm{NEO} 1 \mathrm{NEO} 2}^{2}+g_{\mathrm{NEO} 2}^{2}\right]\right)$. Furthermore, we found significant environmentally mediated effects from Time 1 Communion on Time 2 Extraversion $\left(e_{\mathrm{GOA} 1 \mathrm{NEO} 2}=.10, p<\right.$ $.01)$, Openness $\left(e_{\mathrm{GOA} 1 \mathrm{NEO} 2}=.11, p<.01\right)$, and Conscientiousness $\left(e_{\mathrm{GOA} 1 \mathrm{NEO} 2}=.10, p<.01\right)$. Each of these effects accounted for not more than $3 \%$ of the total environmental variance in the respective traits at Time $2\left(e_{\mathrm{GOA} 1 \mathrm{NEO} 2}^{2} /\left[e_{\mathrm{GOA} 1 \mathrm{NEO} 2}^{2}+e_{\mathrm{NEO} 1 \mathrm{NEO} 2}^{2}+\right.\right.$ $\left.e_{\mathrm{NEO} 2}^{2}\right]$ ).

In a second step, we fitted a series of three-variable Cholesky decomposition models to examine the reverse effects of prior traits on subsequent life goals. That is, controlling for their concurrent links at Time 1, we tested if there were genetic and environmental effects on the Time 2 goal domains accounted for by the five personality traits assessed at Time 1 . We found a significant genetically mediated effect of Time 1 Conscientiousness on subsequent Agency $\left(g_{\mathrm{NEO} 1 \mathrm{GOA} 2}=.13, p<.05\right)$. That is, about $5 \%$ of the total genetic variance in Agency at Time 2 was contributed from genetic effects unique to Conscientiousness at Time 1 $\left(g_{\mathrm{NEO} 1 \mathrm{GOA} 2}^{2} /\left[g_{\mathrm{NEO} 1 \mathrm{GOA} 2}^{2}+g_{\mathrm{GOA} 1 \mathrm{GOA} 2}^{2}+g_{\mathrm{GOA} 2}^{2}\right]\right)$. Regarding Time 2 Communion, we found significant contributions from nonshared environmental variance in Time 1 Extraversion $\left(e_{\mathrm{NEO} 1 \mathrm{GOA} 2}=.10, p<.05\right)$ and Agreeableness $\left(e_{\mathrm{NEO} 1 \mathrm{GOA} 2}=\right.$ $.14, p<.01)$. Again, these cross-time effects were rather small, each accounting for not more than $3 \%$ of the nonshared environmental variance in Communion at Time $2\left(e_{\mathrm{NEO} 1 \mathrm{GOA} 2}^{2} /\right.$ $\left.\left[e_{\mathrm{NEO} 1 \mathrm{GOA} 2}^{2}+e_{\mathrm{GOA} 1 \mathrm{GOA} 2}^{2}+e_{\mathrm{GOA} 2}^{2}\right]\right)$.

\footnotetext{
${ }^{3}$ A comprehensive listing of the fit statistics for the 20 longitudinal multivariate biometric models is available from Wiebke Bleidorn.
} 


\section{Discussion}

Previous research on the interplay between personality traits and the importance of major life goals has revealed significant phenotypic relationships of moderate magnitude both cross-sectionally and over time (Lüdtke et al., 2009; Roberts et al., 2004; Roberts \& Robins, 2000). But what are the etiological sources of these relationships? In view of the predictions derived from the FFT and the NST, the results of our univariate and multivariate biometric models indicate partial support for both conceptions. In the following section, we discuss our findings in light of these contrasting theoretical hypotheses while also considering their general meaning for the theoretical integration of traits and goals as conceptual units in the personality system.

\section{Refining the Phenotypic Picture}

The present study extends previous research not only with regard to its genetically informative design but also with respect to phenotypic results. Unlike prior studies that have focused on data of young adults obtained over periods of two to four years (Lüdtke et al., 2009; Roberts et al., 2004), we studied a sample of middleaged adults over a period of five years.

Despite these differences, phenotypic correlations between the importance of agency and communal goals and the Big Five clearly mirrored previous findings. At both assessments, we revealed significant associations of moderate magnitude between specific sets of traits and the two life goal categories: Importance of agency goals was positively related to Extraversion, Openness, and Conscientiousness and negatively related to Agreeableness, whereas importance of communion goals was positively related to Extraversion, Openness, and Agreeableness. Also consistent with previous research (Roberts et al., 2004; Roberts \& Robins, 2000), there were no significant correlations between Neuroticism and either of the two goal domains.

These results would have been expected by proponents of both theoretical conceptions. From the perspective of the FFT, the significant correlations reflect the inextricable links between the basic Big Five traits and the subordinate goal domains assumed to represent their characteristic manifestations. According to the NST, in contrast, the moderate correlations indicate that traits and goals are related but discrete units in the personality system.

Before discussing the biometric results, we first consider a further interesting phenotypic finding of the present study: In contrast to prior studies that have reported rank-order stabilities of traits and goals in young adults to be about the same size, ranging from .50 to .60 (Lüdtke et al., 2009; Roberts et al., 2004), we revealed considerably higher stabilities in traits than in goals for our middle-aged sample. The higher stabilities of traits in our older sample are in line with a well-established finding termed the cumulative continuity principle (Caspi et al., 2005; Roberts \& Wood, 2006). This describes the tendency for the relative consistency of personality traits to increase with age until it reaches its peak in later adulthood after age 50 years (Roberts \& DelVecchio, 2000). In contrast, we found the stabilities of major life goals to be only slightly greater in middle-aged compared with young adults. This suggests that the cumulative continuity principle cannot be applied to importance ratings of major life goals. That is, although individuals tend to become more consistent with age across all personality traits, the choice of life goals shows the same degree of consistency at different ages across the life course.

\section{How Heritable Are Major Life Goals?}

More crucial than the phenotypic findings are the results of our biometric analyses, starting with the univariate models we applied to assess the heritability of life goal importance. Although both of the contrasted theories assume major life goals show substantial heritabilities, the FFT would expect the genetic effects on goals to be lower than those that have been usually reported for personality traits.

Like personality traits, major life goals seem to be primarily influenced by genes and specific environmental experiences. That is, genetic effects explain a significant amount of variance in both agency- and communion-oriented life goals; the remaining variance can be traced back to nonshared environmental influences, whereas shared environmental effects are negligible. The revealed heritabilities are, however, notably lower compared with those that have been usually reported for broad personality traits (Bouchard \& Loehlin, 2001; Krueger \& Johnson, 2008). Genetic influences explain only about a third of the phenotypic variance in both agency- and communion-oriented life goals, whereas the major part of their variance can be attributed to effects of the nonshared environment. This finding thus supports the FFT, suggesting that major life goals are more susceptible than personality traits to external influences of the environment.

\section{Are There Unique Genetic Effects on Major Life Goals?}

To provide a critical test of the FFT position that genetic effects on goals are completely explained by traits, we extended the univariate approach to a multivariate behavior genetic model. According to the results of these cross-sectional multivariate analyses, a substantial amount of the genetic influences on major life goals were, in fact, explained by the genetic effects on personality traits. In sum, the Big Five accounted for between $40 \%$ and $70 \%$ of the heritable variance in agentic and communal goal importance, indicating that genetic factors that lead to individual differences in these personality traits are also likely to affect individual differences in life goal importance. These effects seem to be rather stable over time, because the proportions of common genetic effects remained the same or even increased, although the total heritabilities of goals have changed across the two measurement occasions.

Although our results point to a considerable genetic overlap between traits and goals, we also revealed significant unique genetic effects on major life goals at both measurement occasions. In line with the NST, this suggests that there are specific genetic factors affecting goals independent of the genetic factors influencing personality traits. These findings clearly conflict with the FFT assumption that major life goals are just characteristic adaptations of personality traits. Rather, they speak for the NST conceptualizing goals as discrete elements of the personality system that are systematically related to personality traits (Roberts \& Robins, 2000).

However, as pointed out by an anonymous reviewer, the FFT does not limit basic personality traits to the five broad domains. 
Specific facet traits are also considered basic tendencies with their own heritable basis independent of the common variance due to the five broad domains (Jang, McCrae, Angleitner, Riemann, \& Livesley, 1998). That is, there might be genetic effects specific to facet traits accounting for the seemingly unique genetic effects on major life goals. We addressed this question by using a strategy similar to the one that has been used by Jang et al. (1998): We corrected the 30 NEO PI-R facet scores for their common domain scale variance by computing the standardized residual of the regression of each facet score on all five domains. We then estimated the correlations between these residual scores and the two goal domains at both Time 1 and Time 2 to identify whether there was specific variance in the facet scales that is substantially linked to Agency and Communion over and above the common variance subsumed by the five domain scales. Out of the 120 correlations, only three coefficients were significantly different from zero at both Time 1 and Time 2. However, these correlations were all smaller than .20 and thus did not explain a substantial amount of variance in the two goal domains. Hence, it seems fair to conclude that the unique genetic variance in Agency and Communion is effectively independent of the genetic effects on both the five broad personality domains and the more specific facet traits.

\section{Are There Common Environmental Effects on the Big Five and Major Life Goals?}

Besides the genetic overlap, we also revealed that about $20 \%$ of the nonshared environmental effects on agency- and communionoriented life goals can be accounted for by nonshared environmental effects on personality traits assessed at the same time. At this point, it is essential to note that nonshared environmental effects were modeled as residual variance also containing influences of random effects and method specificity. The results of our crosssectional multivariate analyses thus should be considered a first hint for the existence of common environmental effects influencing both traits and goals, because we could not rule out common method-specific effects.

However, the findings of our longitudinal multivariate analyses back up the assumption of common nonshared environmental effects that systematically influence both traits and goals even across a considerable period of time. Supposing that these effects reflect true nonshared environmental variance, the present results suggest that specific environmental factors make twins more different in terms of their personality traits, which also lead to individual differences in major life goals. With regard to the theoretical conceptions at issue, these results support the NST, assuming goals and traits are related but distinct units that are affected by unique as well as common environmental influences.

The finding of a significant overlap in the nonshared environmental effects on traits and goals raises another question concerning the specific variables of the nonshared environment likely to affect both personality traits and goals. Until now, attempts to identify and measure variables of the nonshared environment that influence personality have been less effective, leading some researchers to conclude that the factors underlying nonshared environmental variance "remain outside the domain of systematic scientific investigation" (Turkheimer \& Waldron, 2000, p. 93). The present findings, however, suggest that there is some system to this source of variance and thus argue for a continuation of the search for measurable variables in the nonshared environment that are likely to affect personality. Referring to the NST, this search might be more fruitful by operationalizing the social environment in terms of social roles located in important life domains, such as work, family, or community, that are likely to affect both traits and goals (Roberts \& Wood, 2006).

\section{Are There Cross-Time Effects Between the Big Five and Major Life Goals?}

Although the multivariate cross-sectional findings point to the fact that traits and goals are distinct units, they do not disclose their interplay over time. Are traits and goals complementary units of the personality system, implying that there are reciprocal effects over time (Robert et al., 2004; Roberts \& Robins, 2000)? Or should traits be considered impervious to genetically and environmentally mediated effects from goals (McCrae \& Costa, 2008)?

Before we discuss the findings of our multivariate longitudinal biometric analyses, it is essential to note that we explicitly tested for genetically and environmentally mediated cross-variablecross-time effects that were unique to the Time 1 goals and traits, respectively (i.e., independent of their common variance at the first measurement occasion). Our findings thus do not negate the possibility of further cross-variable-cross-time effects reflecting the concurrent relationships between traits and goals at the first measurement occasion.

The pattern of prospective effects of the Big Five on the two life goal dimensions approximately mirrored the pattern of concurrent phenotypic correlations. That is, genetic effects on Conscientiousness at an earlier measurement occasion affect agentic life goals at a later date. Later communal goals, however, are partly influenced by nonshared environmental factors influencing Extraversion and Agreeableness at an earlier date. In line with both the FFT and the NST, it thus seems fair to assume that individuals do adapt their life goals according to their preexisting personality traits, even over longer periods of time.

More controversial than the cross-time effects of prior traits on later goals were the findings of our reverse analyses aimed at examining the effects of prior goals on later traits. The significant, although small, genetically and environmentally mediated effects of prior life goals on subsequent personality traits support the NST while assuming goals are more than just a conduit for traits. In view of these results, goals might be considered proxies for anticipated contexts, leading people to adapt their personality traits in advance of upcoming social demands (Roberts et al., 2004). A further implication of these results concerns the FFT assumption that traits are more basic than life goals. Instead of a causal precedence of traits over major life goals, our findings speak for a reciprocal interplay between traits and goals over time. That is, people do not only adapt their life goals to their preexisting personality traits but also adjust their traits in the service of pursuing their major strivings in life.

\section{Limitations and Future Directions}

The present study extends previous research by using a multivariate longitudinal-biometric design to disentangle the underlying genetic and environmental sources of the structural links between 
traits and goals cross-sectionally as well as over time. Yet, several limitations could be addressed by future research.

First, the sample size is only moderate for a twin study, limiting the statistical power of our biometric analyses. As is typical for voluntary twin samples, there is also an overrepresentation of women relative to men as well as $\mathrm{MZ}$ relative to $\mathrm{DZ}$ twin pairs. It should be noted, however, that our phenotypic results mainly replicate findings of previous studies with larger samples that have also revealed comparable results for subsamples of males and females (e.g., Lüdtke et al., 2009).

Second, analyses were performed on data from just two points of measurement. Researchers conducting future genetically informative studies realizing multiple assessments are encouraged to use more advanced analytic approaches, like biometric growth curve models (e.g., Bleidorn et al., 2009). Such multiwave studies would not only allow for the examination of the shape and sources of the developmental trajectories in traits and goals but would also permit a critical test of the mechanisms described by the corresponsive principle (Caspi et al., 2005; Roberts et al., 2004).

We also reiterate that nonshared environmental effects were measured as residual variance and were thus confounded with residual causes in addition to nonshared environmental influences comprising random error and method-specific effects. Multimethod twin studies are desired to disentangle valid genetic and nonshared environmental effects from systematic and unsystematic method-specific variance (e.g., Kandler et al., 2010).

Finally, gene-environment correlations and/or interactions might have affected our estimates of genetic and environmental effects. That is, our results relate exclusively to overall population levels. For potential gene-environment correlations and/or interactions to be examined appropriately, future studies are needed that specify and measure theoretically meaningful environmental variables and/or alleles at specific loci that might possibly affect the common and unique genetic-environmental effects on traits and goals (Purcell, 2002).

\section{Conclusions}

The present study was aimed at shedding some further light on the interplay between personality traits and major life goals, particularly with regard to controversial theoretical postulates about their underlying genetic and environmental sources. Our findings provide partial support for assumptions of both the FFT and the NST. In line with the FFT, the relatively lower heritabilities of major life goals indicate that goals are more susceptible to external influences of the environment than are personality traits. However, consistent with the NST, it seems fair to assume that personality traits and major life goals are related but distinct elements of the personality system and are affected by both common and specific genetic and environmental influences. Instead of a causal precedence of traits over goals, both might be better conceptualized as complementary units of the personality system. That is, people do not only calibrate their goals in accordance with their personality traits but also adjust their traits to their major life goals to adapt adequately to the demands of their current or anticipated social environment.

These seemingly conflicting findings can be reasonably conciliated in terms of the conceptual framework offered by McAdams and Pals (2006). Also addressing the differences between traits and characteristic adaptations, these authors adopted an intermediate position between the FFT and the NST. In particular, agreeing with the FFT, their framework considers characteristic adaptations to be more specific and malleable than traits. Also, traits are assumed to exert some influence on some characteristic adaptations. Consistent with the NST, however, not all characteristic adaptations are thought of as simple by-products of the interaction between traits and the environment. Rather, it is explicitly acknowledged that certain characteristic adaptations, like major life goals, can have their own and independent importance, developmental trajectory, and function.

On this note, our results put emphasis on a very important point that has been previously described as the "unique historical mission" (McAdams \& Pals, 2006, p. 204) of personality psychology. Namely, it is worthwhile to study the elements of the personality system, such as traits, goals, skills, and so on, together but also in their own right so as to provide a comprehensive framework for understanding the whole person. Of course, a person can adequately be described as being high on Agreeableness with all its implicit connotations - however, further valuable information can be found in the underlying observations that the person, for instance, aims to become a social worker, likes to volunteer his or her time, and is quite good at settling disputes (McCrae, 1996). Thus, a comprehensive understanding of personality function and development requires a detailed consideration of the full range of elements relevant to the personality system in order to exploit their separate as well as their joint contributions to the way individuals shape their lives.

\section{References}

Allport, G. W. (1937). Personality: A psychological interpretation. New York, NY: Holt.

Arbuckle, J. L. (2007). AMOS users guide 17.0. Chicago, IL: SPSS.

Austin, J. T., \& Vancouver, J. B. (1996). Goal constructs in psychology: Structure, process, and content. Psychological Bulletin, 120, 338-375. doi:10.1037/0033-2909.120.3.338

Bakan, D. (1966). The duality of human existence: Isolation and communion in Western man. Boston, MA: Beacon Press.

Becker, A., Busjahn, A., Faulhaber, H. D., Bähring, S., Robertson, J., Schuster, H., \& Luft, F. C. (1997). Twin zygosity automated determination with microsatellites. Journal of Reproductive Medicine, 42, 260 266.

Bleidorn, W. (2009). Linking personality states, current social roles and major life goals. European Journal of Personality, 23, 509-530. doi: $10.1002 /$ per.731

Bleidorn, W., Kandler, C., Riemann, R., Angleitner, A., \& Spinath, F. M. (2009). Patterns and sources of adult personality development: Growth curve analyses of the NEO PI-R scales in a longitudinal twin study. Journal of Personality and Social Psychology, 97, 142-155. doi: 10.1037/a0015434

Borkenau, P., Riemann, R., Angleitner, A., \& Spinath, F. M. (2002). Similarity of childhood experiences and personality resemblance in monozygotic and dizygotic twins: A test of the equal environments assumption. Personality and Individual Differences, 33, 261-269.

Bouchard, T. J. J., \& Loehlin, J. C. (2001). Genes, evolution, and personality. Behavior Genetics, 31, 243-273. doi:10.1023/A:1012294324713

Cantor, N., Norem, J. K., Niedenthal, P. M., Langston, C. A., \& Brower, A. M. (1987). Life tasks, self-concept ideals, and cognitive strategies in a life transition. Journal of Personality and Social Psychology, 53, 1178-1191.

Caspi, A., Roberts, B. W., \& Shiner, R. L. (2005). Personality develop- 
ment: Stability and change. Annual Review of Psychology, 56, 453-484. doi:10.1146/annurev.psych.55.090902.141913

Cohen, J. (1992). A power primer. Psychological Bulletin, 112, 155-159.

Costa, P. T. J., \& McCrae, R. R. (1992). Revised NEO Personality Inventory (NEO PI-R) and NEO Five-Factor Inventory: Professional manual. Odessa, FL: Psychological Assessment Resources.

Hofer, J., \& Chasiotis, A. (2003). Congruence of life goals and implicit motives as predictors of life satisfaction: Cross-cultural implications of a study of Zambian male adolescents. Motivation and Emotion, 27, 251-272.

Hogan, R., \& Roberts, B. W. (2000). A socioanalytic perspective on person-environment interaction. In W. B. Walsh, K. H. Craik, \& R. H. Price (Eds.), Person-environment psychology: New directions and perspectives (2nd ed., pp. 1-23). Mahwah, NJ: Erlbaum.

Jang, K. L., McCrae, R. R., Angleitner, A., Riemann, R., \& Livesley, W. J. (1998). Heritability of facet-level traits in a cross-cultural twin sample: Support for a hierarchical model of personality. Journal of Personality and Social Psychology, 74, 1556-1565.

John, O. P., Naumann, L. P., \& Soto, C. J. (2008). Paradigm shift to the integrative Big Five trait taxonomy: History, measurement, and conceptual issues. In O. P. John, R. W. Robins, \& L. A. Pervin (Eds.), Handbook of personality: Theory and research (3rd ed., pp. 114-158). New York, NY: Guilford Press.

Johnson, A. M., Vernon, P. A., \& Feiler, A. R. (2008). Behavioral genetic studies of personality: An introduction and review of the results of 50+ years of research. In G. J. Boyle, G. Matthews, \& D. H. Saklofske (Eds.), Personality theory and assessment (pp. 145-173). London, Great Britain: Sage.

Kandler, C., Bleidorn, W., Riemann, R., Spinath, F. M., Thiel, W., \& Angleitner, A. (2010). Sources of cumulative continuity in personality: A longitudinal multiple-rater twin study. Journal of Personality and Social Psychology, 98, 995-1008. doi:10.1037/a0019558

Kandler, C., Riemann, R., \& Kämpfe, N. (2009). Genetic and environmental mediation between measures of personality and family environment in twins reared together. Behavior Genetics, 39, 24-35. doi:10.1007/ s10519-008-9238-8

Kandler, C., Riemann, R., Spinath, F. M., \& Angleitner, A. (in press). Sources of variance in personality facets: A twin study of self-self, peer-peer, and self-peer (dis-) agreement. Journal of Personality.

Kasser, T., \& Ryan, R. M. (1996). Further examining the American dream: Differential correlates of intrinsic and extrinsic goals. Personality and Social Psychology Bulletin, 22, 280-287. doi:10.1177/ 0146167296223006

Klinger, E. (1977). Meaning and void: Inner experience and the incentives in people's lives. Minneapolis, MN: University of Minnesota Press.

Krueger, R. F., \& Johnson, W. (2008). Behavioral genetics and personality: A new look at the integration of nature and nurture. In O. P. John, R. Robins, \& L. A. Pervin (Eds.), Handbook of personality: Theory and research (3rd ed., pp. 287-310). New York, NY: Guilford Press.

Little, B. R. (1983). Personal projects: A rationale and method for investigation. Environment and Behavior, 15, 273-309. doi:10.1177/ 0013916583153002

Little, R. J. A. (1988). A test of missing completely at random for multivariate data with missing values. Journal of the American Statistical Association, 83, 1198-1202.

Lüdtke, O., Trautwein, U., \& Husemann, N. (2009). Goal and personality trait development in a transitional period: Assessing change and stability in personality development. Personality and Social Psychology Bulletin, 35, 428-441. doi:10.1177/0146167208329215

Martin, N. G., Eaves, L. J., Kearsey, M. J., \& Davies, P. (1978). The power of the classical twin study. Heredity, 40, 97-116.

Maslow, A. H. (1954). Motivation and personality. New York, NY: Harper \& Row.
McAdams, D. P. (1988). Power, intimacy and the life story: Personological inquiries into identity. Homewood, IL: Dorsey Press.

McAdams, D. P., \& Pals, J. (2006). A new Big Five: Fundamental principles for an integrative science of personality. American Psychologist, 61, 204-217. doi:10.1037/0003-066X.61.3.204

McClelland, D. C. (1961). The achieving society. Princeton, NJ: Van Nostrand.

McClelland, D. C. (1985). Human motivation. Glenview, IL: Scott, Foresman.

McCrae, R. R. (1996). Integrating the levels of personality. Psychological Inquiry, 7, 353-356. doi:10.1207/s15327965pli0704_10

McCrae, R. R., \& Costa, P. T., Jr. (1999). A five-factor theory of personality. In L. A. Pervin \& O. P. John (Eds.), Handbook of personality: Theory and research (2nd ed., pp. 139-153). New York, NY: Guilford Press.

McCrae, R. R., \& Costa, P., Jr. (2008). The five-factor theory of personality. In O. P. John, R. W. Robins, \& L. A. Pervin (Eds.), Handbook of personality: Theory and research (3rd ed., pp. 1-58). New York, NY: Guilford Press.

McCrae, R. R., Costa, P. T., Jr., Ostendorf, F., Angleitner, A., Hrebickova, M., Avia, M. D., . . Smith, P. B. (2000). Nature over nurture: Temperament, personality, and life span development. Journal of Personality and Social Psychology, 78, 173-186.

McCrae, R. R., \& John, O. P. (1992). An introduction to the five-factor model and its applications. Journal of Personality, 6, 175-215.

Murray, H. A. (1938). Explorations in personality. New York, NY: Oxford University Press.

Neale, M. C., \& Maes, H. H. (2004). Methodology for genetic studies of twins and families. Dordrecht, the Netherlands: Kluwer Academic.

Nurmi, J. E., \& Salmela-Aro, K. (2002). Goal construction, reconstruction and depressive symptoms in a life-span context: The transition from school to work. Journal of Personality, 70, 385-420. doi:10.1111/14676494.05009

Onisczenko, W., Angleitner, A., Strelau, J., \& Angert, T. (1993). The questionnaire of twins' physical resemblance. Unpublished manuscript, Department of Psychology, University of Warsaw, Warsaw, Poland.

Ostendorf, F., \& Angleitner, A. (2004). NEO-Persönlichkeitsinventar nach Costa und McCrae: Revidierte Fassung. [NEO Personality Inventory by Costa and McCrae: Revised edition]. Göttingen, Germany: Hogrefe.

Pöhlmann, K., \& Brunstein, J. C. (1997). GOALS: Ein Fragebogen zur Messung von Lebenszielen [GOALS: A questionnaire for assessing life goals]. Diagnostica, 43, 63-79.

Purcell, S. (2002). Variance components models for gene-environment interaction in twin analysis. Twin Research and Human Genetics, 5, 554-571. doi:10.1375/twin.5.6.554

Riemann, R., Angleitner, A., \& Strelau, J. (1997). Genetic and environmental influences on personality: A study of twins reared together using the self- and peer report NEO-FFI scales. Journal of Personality, 65, 449-475. doi:10.1111/j.1467-6494.1997.tb00324.x

Roberts, B. W., \& DelVecchio, W. F. (2000). The rank-order consistency of personality traits from childhood to old age: A quantitative review of longitudinal studies. Psychological Bulletin, 126, 3-25. doi:10.1037// 0033-2909.126.1.3

Roberts, B. W., O'Donnell, M., \& Robins, R. W. (2004). Goal and personality trait development in emerging adulthood. Journal of Personality and Social Psychology, 87, 541-550. doi:10.1037//00332909.126.1.3

Roberts, B. W., \& Robins, R. W. (2000). Broad dispositions, broad aspirations: The intersection of personality traits and major life goals. Personality and Social Psychology Bulletin, 26, 1284-1296.

Roberts, B. W., \& Wood, D. (2006). Personality development in the context of the neo-socioanalytic model of personality. In D. K. Mroczek \& T. D. Little (Eds.), Handbook of personality development (pp. 11-39). Mahwah, NJ: Erlbaum. 
Romero, E., Villar, P., Luengo, M. A., \& Gomez-Fraguela, J. A. (2009). Traits, personal strivings and well-being. Journal of Research in Personality, 43, 535-546. doi:10.1016/j.jrp.2009.03.006

Salmela-Aro, K., Aunola, K., \& Nurmi, J. E. (2007). Personal goals during emerging adulthood: A 10-year follow up. Journal of Adolescent Research, 22, 690-715. doi:10.1177/0743558407303978

Sheldon, K. M., \& Cooper, M. L. (2008). Goal striving within agentic and communal roles: Separate but functionally similar pathways to enhanced well-being. Journal of Personality, 76, 415-447. doi:10.1111/j.14676494.2008.00491.x

Spinath, F. M., Wolf, H., Angleitner, A., Borkenau, P., \& Riemann, R. (2005). Multimodale Untersuchung von Persönlichkeiten und kognitiven Fähigkeiten: Ergebnisse der deutschen Zwillingsstudien BILSAT und GOSAT [Multimodal investigation of personality and cognitive ability: Results from two German twin studies BiLSAT and GOSAT]. Zeitschrift für Soziologie der Erziehung, 25, 146-161.

Terracciano, A., Costa, P. T. J., \& McCrae, R. R. (2006). Personality plasticity after age 30. Personality and Social Psychology Bulletin, 32, 999-1009. doi:10.1177/0146167206288599

Turkheimer, E., \& Waldron, M. (2000). Nonshared environment: A theoretical, methodological, and quantitative review. Psychological Bulletin, 126, 78-108. doi:10.1037//0033-2909.126.1.78

Watson, D. (2004). Stability versus change, dependability versus error: Issues in the assessment of personality over time. Journal of Research in Personality, 38, 319-350.

Winell, M. (1987). Personal goals: The key to self-direction in adulthood. In M. Ford \& D. Ford (Eds.), Humans as self-constructing living systems: Putting the framework to work (pp. 261-287). Hillsdale, NJ: Erlbaum.

Received November 17, 2009

Revision received February 28, 2010

Accepted April 12, 2010

\section{Members of Underrepresented Groups: Reviewers for Journal Manuscripts Wanted}

If you are interested in reviewing manuscripts for APA journals, the APA Publications and Communications Board would like to invite your participation. Manuscript reviewers are vital to the publications process. As a reviewer, you would gain valuable experience in publishing. The P\&C Board is particularly interested in encouraging members of underrepresented groups to participate more in this process.

If you are interested in reviewing manuscripts, please write APA Journals at Reviewers@apa.org. Please note the following important points:

- To be selected as a reviewer, you must have published articles in peer-reviewed journals. The experience of publishing provides a reviewer with the basis for preparing a thorough, objective review.

- To be selected, it is critical to be a regular reader of the five to six empirical journals that are most central to the area or journal for which you would like to review. Current knowledge of recently published research provides a reviewer with the knowledge base to evaluate a new submission within the context of existing research.

- To select the appropriate reviewers for each manuscript, the editor needs detailed information. Please include with your letter your vita. In the letter, please identify which APA journal(s) you are interested in, and describe your area of expertise. Be as specific as possible. For example, "social psychology" is not sufficient-you would need to specify "social cognition" or "attitude change" as well.

- Reviewing a manuscript takes time (1-4 hours per manuscript reviewed). If you are selected to review a manuscript, be prepared to invest the necessary time to evaluate the manuscript thoroughly. 